\title{
Molecular epidemiology of drug resistant Mycobacterium tuberculosis in Africa: a systematic review
}

\author{
Namaunga Kasumu Chisompola ${ }^{1,2^{*}}$, Elizabeth Maria Streicher ${ }^{1}$, Chishala Miriam Kapambwe Muchemwa ${ }^{2}$, \\ Robin Mark Warren ${ }^{1}$ and Samantha Leigh Sampson ${ }^{1}$
}

\begin{abstract}
Background: The burden of drug resistant tuberculosis in Africa is largely driven by the emergence and spread of multidrug resistant (MDR) and extensively drug resistant (XDR) Mycobacterium tuberculosis strains. MDR-TB is defined as resistance to isoniazid and rifampicin, while XDR-TB is defined as MDR-TB with added resistance to any of the second line injectable drugs and any fluoroquinolone.

The highest burden of drug resistant TB is seen in countries further experiencing an HIV epidemic. The molecular mechanisms of drug resistance as well as the evolution of drug resistant TB strains have been widely studied using various genotyping tools. The study aimed to analyse the drug resistant lineages in circulation and transmission dynamics of these lineages in Africa by describing outbreaks, nosocomial transmission and migration. Viewed as a whole, this can give a better insight into the transmission dynamics of drug resistant TB in Africa.
\end{abstract}

Methods: A systematic review was performed on peer reviewed original research extracted from PubMed reporting on the lineages associated with drug resistant TB from African countries, and their association with outbreaks, nosocomial transmission and migration. The search terms "Tuberculosis AND drug resistance AND Africa AND (spoligotyping OR molecular epidemiology OR IS6110 OR MIRU OR DNA fingerprinting OR RFLP OR VNTR OR WGS)" were used to identify relevant articles reporting the molecular epidemiology of drug resistant TB in Africa.

Results: Diverse genotypes are associated with drug resistant TB in Africa, with variations in strain predominance within the continent. Lineage 4 predominates across Africa demonstrating the ability of "modern strains" to adapt and spread easily. Most studies under review reported primary drug resistance as the predominant type of transmission. Drug resistant TB strains are associated with community and nosocomial outbreaks involving MDRand XDR-TB strains. The under-use of molecular epidemiological tools is of concern, resulting in gaps in knowledge of the transmission dynamics of drug resistant TB on the continent.

Conclusions: Genetic diversity of M. tuberculosis strains has been demonstrated across Africa implying that diverse genotypes are driving the epidemiology of drug resistant TB across the continent.

Keywords: Mycobacterium tuberculosis, Drug resistance, Africa, Molecular epidemiology

\footnotetext{
* Correspondence: unga_k@yahoo.co.uk

${ }^{1}$ DST/NRF Centre of Excellence for Biomedical Tuberculosis Research/South

African Medical Research Council Centre for Tuberculosis Research, Division

of Molecular Biology and Human Genetics, Faculty of Medicine and Health

Sciences, Stellenbosch University, Cape Town, South Africa

${ }^{2}$ Department of Basic Medical Sciences, Michael Chilufya Sata School of

Medicine, Copperbelt University, Ndola, Zambia
}

(c) The Author(s). 2020 Open Access This article is licensed under a Creative Commons Attribution 4.0 International License, which permits use, sharing, adaptation, distribution and reproduction in any medium or format, as long as you give appropriate credit to the original author(s) and the source, provide a link to the Creative Commons licence, and indicate if changes were made. The images or other third party material in this article are included in the article's Creative Commons licence, unless indicated otherwise in a credit line to the material. If material is not included in the article's Creative Commons licence and your intended use is not permitted by statutory regulation or exceeds the permitted use, you will need to obtain permission directly from the copyright holder. To view a copy of this licence, visit http://creativecommons.org/licenses/by/4.0/. The Creative Commons Public Domain Dedication waiver (http://creativecommons.org/publicdomain/zero/1.0/) applies to the data made available in this article, unless otherwise stated in a credit line to the data. 


\section{Background}

Multidrug resistant tuberculosis (MDR-TB) is defined as resistance to isoniazid and rifampicin, the most potent anti-TB drugs, while extensively drug resistant tuberculosis (XDR-TB) is defined as MDR-TB with additional resistance to any of the second line injectable drugs (aminoglycosides) and any fluoroquinolone (FQ) [1, 2]. Rifampicin resistance (RR) is used as a proxy for MDR-TB and rapid detection of $R R$ strains is recommended $[1,2]$.

\section{Burden of drug resistant tuberculosis in Africa}

Globally, an estimated 10 million people developed TB in 2017 alone with over half a million estimated RR-TB cases (82\% of which had MDR-TB) [1]. Close to $50 \%$ of MDR/RR-TB cases were reported in three countries, namely; India, China and Russian Federation. In 2017, 26,845 MDR/RR-TB and 867 XDR-TB cases were notified in Africa [1]. Of the notified MDR/RR- and XDRTB cases, treatment enrolment was significantly low (21\% for MDR/RR-TB and $1 \%$ for XDR-TB) [1]. The highest proportion of TB/HIV co-infection is also seen in this continent ( $31 \%$ on average), with some regions having co-infection rates higher than $50 \%$ [1, 3]. It is therefore important to identify TB/HIV co-morbidity in these high risk areas.

\section{Treatment regimens implemented}

Up to 2018, the World Health Organisation (WHO) recommended that MDR-TB be treated with a standard regimen of second line anti-TB drugs which includes a combination of an injectable drug, a fluoroquinolone, other core anti-TB agents as well as the first line anti-TB drugs pyrazinamide and ethambutol, subject to drug susceptibility testing (DST) results [2]. These drugs are however less potent, more toxic and require a prolonged treatment period of up to 24 months. More recently however, the WHO has endorsed a shorter 9-12 month regimen which has been demonstrated to be equally effective in the treatment of MDR-TB and consists of a combination of anti-TB agents [3, 4]. Since 2014, at least 12 countries have introduced this short MDR-TB regimen in Africa [4]. Inappropriate implementation of the shorter MDR-TB treatment regimen however poses a risk of acquiring additional resistance in affected patients, as currently observed for the longer MDR-TB treatment regimen [3, 4]. It is in this light that the WHO recommends DST before commencement of treatment and that the shorter regimen only be made available to patients that have not received prior MDR-TB treatment [4]. Furthermore, the shorter MDR-TB regimen is not recommended for patients with second-line drug resistance, pregnant patients and patients with extrapulmonary TB [4].

\section{Diagnosis of drug resistant tuberculosis}

Culture-based phenotypic DST (pDST) remains the gold standard for the diagnosis of drug resistant TB [1]. The WHO has however endorsed the use of nucleic acid tests (NATs) such as the GeneXpert MTB/RIF assay and the molecular line probe assay (LPA), which provide a more rapid diagnosis [1]. However, they are limited in the range of drug susceptibility that can be detected [1]. Furthermore, the running costs associated with these techniques, the need for expertise and the lack of availability at point of care could explain the low uptake of these rapid diagnostic tools across Africa.

The diagnostic algorithm for drug resistant $\mathrm{TB}$ varies across Africa with 15 out of 25 high TB and high MDRTB burden countries being listed as having a national policy that recommends the use of rapid diagnostic tools as the initial diagnostic tool for presumptive TB [1]. Furthermore 12 out of 25 high TB and high MDR-TB burden countries in Africa are reported as having a national policy for universal pDST [1]. However the number of cases tested with rapid diagnostic tests and pDST is highly variable, with largely poor diagnostic coverage, demonstrating that a high proportion of drug resistant cases go undetected. Of concern is the low rate of DST results for rifampicin and second line drugs. Overall, there is a need to strengthen laboratory capacity and to increase uptake of rapid diagnostic tools in order to improve case detection and treatment of drug resistant $\mathrm{TB}$ in Africa.

\section{Drug resistance tuberculosis surveillance}

Routine and frequent epidemiological surveillance is critical for understanding the burden of drug resistant $\mathrm{TB}$ in a given region and for planning and policy development and policy implementation. The major drug resistance TB surveillance methods that have been used in Africa include case notifications combined with expert opinions, prevalence surveys, and capture-recapture to estimate incidence [1]. However, the most effective drug resistance monitoring tool has been demonstrated to be continuous surveillance of TB patients through pDST and systematic analysis of routinely collected data [1]. It is a concern that there is scanty data on the prevalence of drug resistant TB across Africa [1].

Between 2010 and 2015, only 16 of 54 African countries $(30 \%)$ completed national drug resistance prevalence surveys [1]. Older drug resistance survey data is available from 8 countries for the period 2005 and 2009 [1]. Since 2016, there were drug resistance TB surveys on-going in 7 countries while fourteen countries in Africa currently do not have any survey data [1]. From the countries with repeat drug resistance survey data, some countries have reported an increase in the prevalence of MDR-TB and drug resistant TB in general $[5,6]$. Other 
countries have demonstrated no significant changes in prevalence rates of drug resistant TB [7-9].

\section{Molecular typing tools in epidemiological investigations} Since mid-1990s, several techniques have been validated for use in molecular epidemiological investigations of $M$. tuberculosis strain diversity and clustering including spacer oligonucleotide typing (spoligotyping), insertion sequence 6110-based restriction fragment length polymorphism (IS6110-RFLP) and Mycobacterial Interspersed Repetitive Units - Variable Number Of Tandem Repeats (MIRU-VNTR) [10-12]. Furthermore, next generation whole genome sequencing (WGS) of $M$. tuberculosis clinical isolates provides invaluable knowledge on genetic diversity and microevolution of the $M$. tuberculosis genomes in circulation [13]. Whole genome sequencing is preferred to other typing techniques due to the robustness and high resolution offered by the technique [13]. It however does not negate the usefulness of other typing tools due to limitations experienced in resource limited countries. These include the lack of expertise to set up libraries and to analyse sequencing data, the cost of equipment and the general running cost.

Several epidemiological studies have been conducted across Africa, focused on drug resistance, transmission dynamics and the population structure of drug resistant TB strains [14-16]. However, there is very limited systematic data on the molecular epidemiology of drug resistant TB in Africa. This review therefore aims to synthesise available knowledge of drug resistant TB in Africa, with a particular focus on lineages in circulation, and lineages associated with outbreaks, nosocomial transmission and migration.

\section{Methods}

\section{Search strategy and selection criteria}

A systematic review was conducted of peer reviewed original research on the molecular epidemiology of drug resistant TB from African countries, extracted from PubMed on July 3, 2019 for relevant articles published between 1999 and 2019. The search terms "Tuberculosis AND drug resistance AND Africa AND individual country name for all 54 African countries AND (spoligotyping OR molecular epidemiology OR IS6110 OR MIRU OR DNA fingerprinting OR RFLP OR VNTR OR WGS)" were used to identify relevant articles reporting the molecular epidemiology of drug resistance in Africa. Studies were eligible for inclusion in the analysis if they described the lineages associated with drug resistant $\mathrm{TB}$, outbreaks, nosocomial transmission and migration in any African countries using one or more of the following techniques; spoligotyping or IS6110 RFLP or MIRU VNTR or WGS. The search resulted in 187 articles of which 55 met the inclusion criteria, as summarised in Table 1 . To generate the review, the following variables were extracted from the studies; pDST, proportion of clustered drug resistant strains, HIV/TB coinfection rate and genotyping methods.

\section{Results \\ Overview of drug resistant Mycobacterium tuberculosis strain types in Africa Molecular epidemiological data}

The molecular mechanisms of drug resistance as well as the evolution of drug resistant strains in Africa have been studied using a variety of genotyping tools [10-13]. This has provided some insight into the transmission dynamics of drug resistant TB. Most studies (89\%) under review here have used spoligotyping to describe the molecular epidemiology of drug resistant TB in Africa although there are a number of studies which have used highly discriminatory methods which include WGS, IS6110-RFLP and MIRU-VNTR [13-16].

\section{Population structure of drug resistant TB genotypes in Africa}

Sporadic molecular mycobacteriological studies have been conducted within Africa (Figs. 1 and 2), with South Africa having the vast majority of data on the continent. Diverse genotypes have been associated with drug resistant TB (Fig. 1, Fig. 2, Table 1), with particular genotypes being more predominant $[52,58,59,66,71]$. For instance, the Beijing genotype is widespread across parts of Africa $[38,44,60]$. The population structure of drug resistant $\mathrm{TB}$ is however not homogeneous (Figs. 1 and 2), with certain strains being more predominant in specific population groups [26, 38, 53, 72, 73]. For example, the Haarlem and CAS genotypes are predominantly associated with drug resistance including MDR-TB in parts of North and East Africa while in Southern and West Africa the Beijing and LAM genotypes are highly associated with drug resistance (Figs. 1 and 2) [28, 30, 34, 45, 61, 65, 72]. Further, country-wise comparisons show a correlation between genotypes associated with drug susceptible $\mathrm{TB}$ and drug resistant $\mathrm{TB}$, implying that drug resistant $\mathrm{TB}$ is to a large extent acquired by individuals within their respective African countries [14, 16, 45, 66, 74].

Associations between specific drug resistant TB strains and HIV co-infection have been noted, with high mortality rates being observed in the context of TB/HIV coinfection [56, 64, 74]. Genotypes such as Beijing, Haarlem and LAM have been associated with high levels of drug resistance and high mortality rates in both HIV seropositive and seronegative individuals $[50,51,57,65]$. A clear distinction has been observed in the population structure of genotypes associated with mono-resistance, MDR- and XDR-TB (Table 1). In parts of South Africa the F15/LAM4/KZN and Beijing genotypes have been 


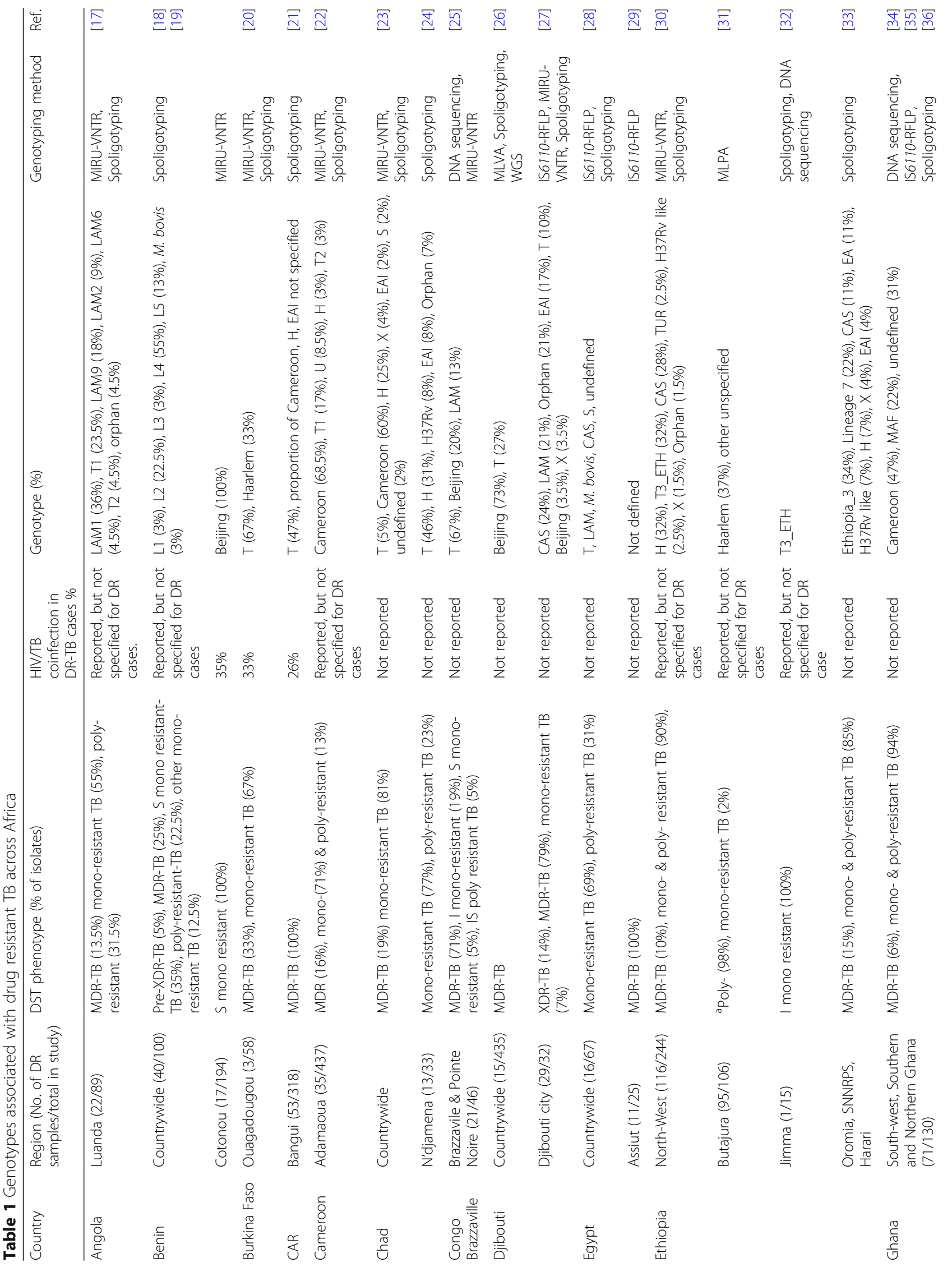




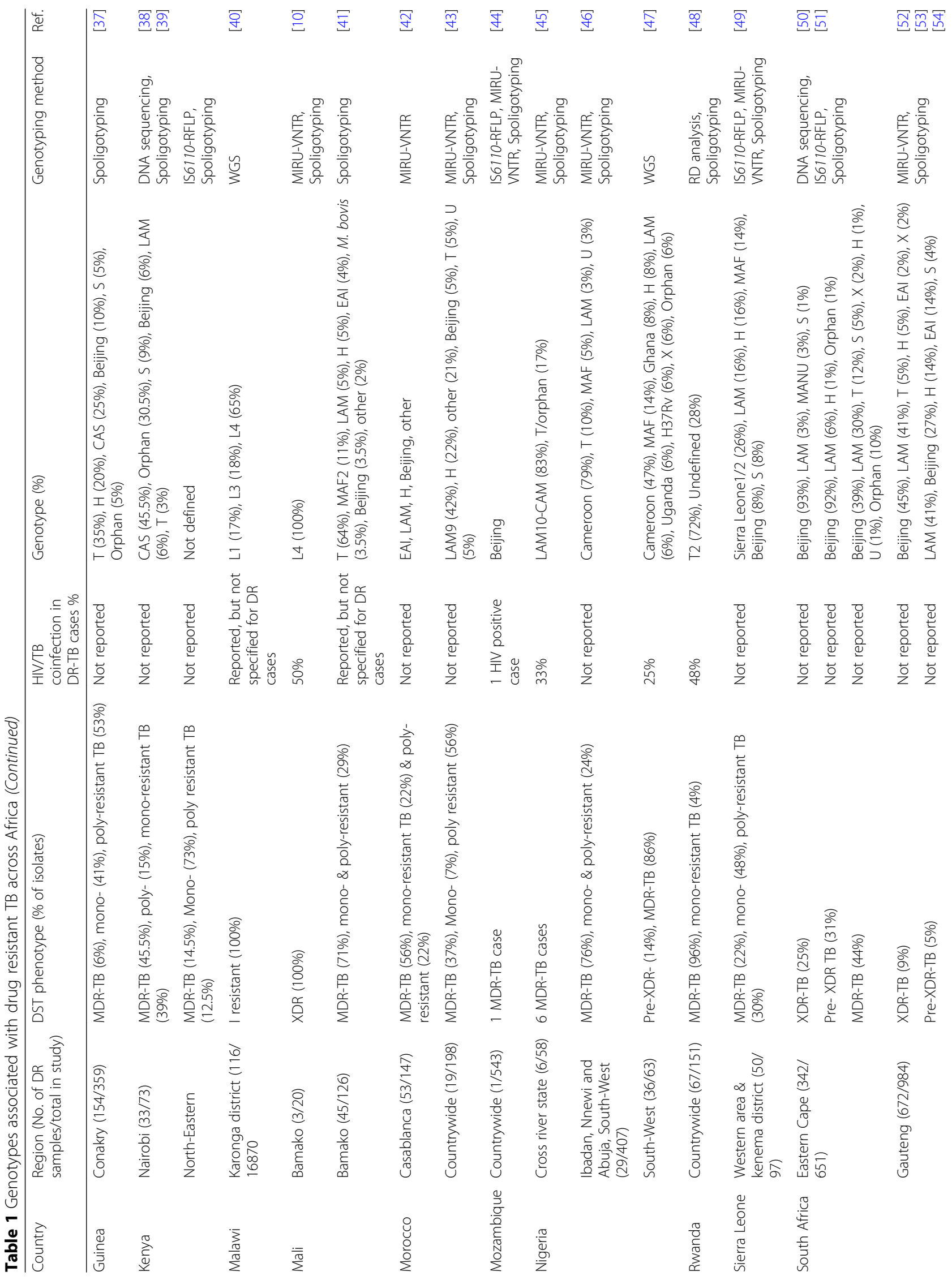




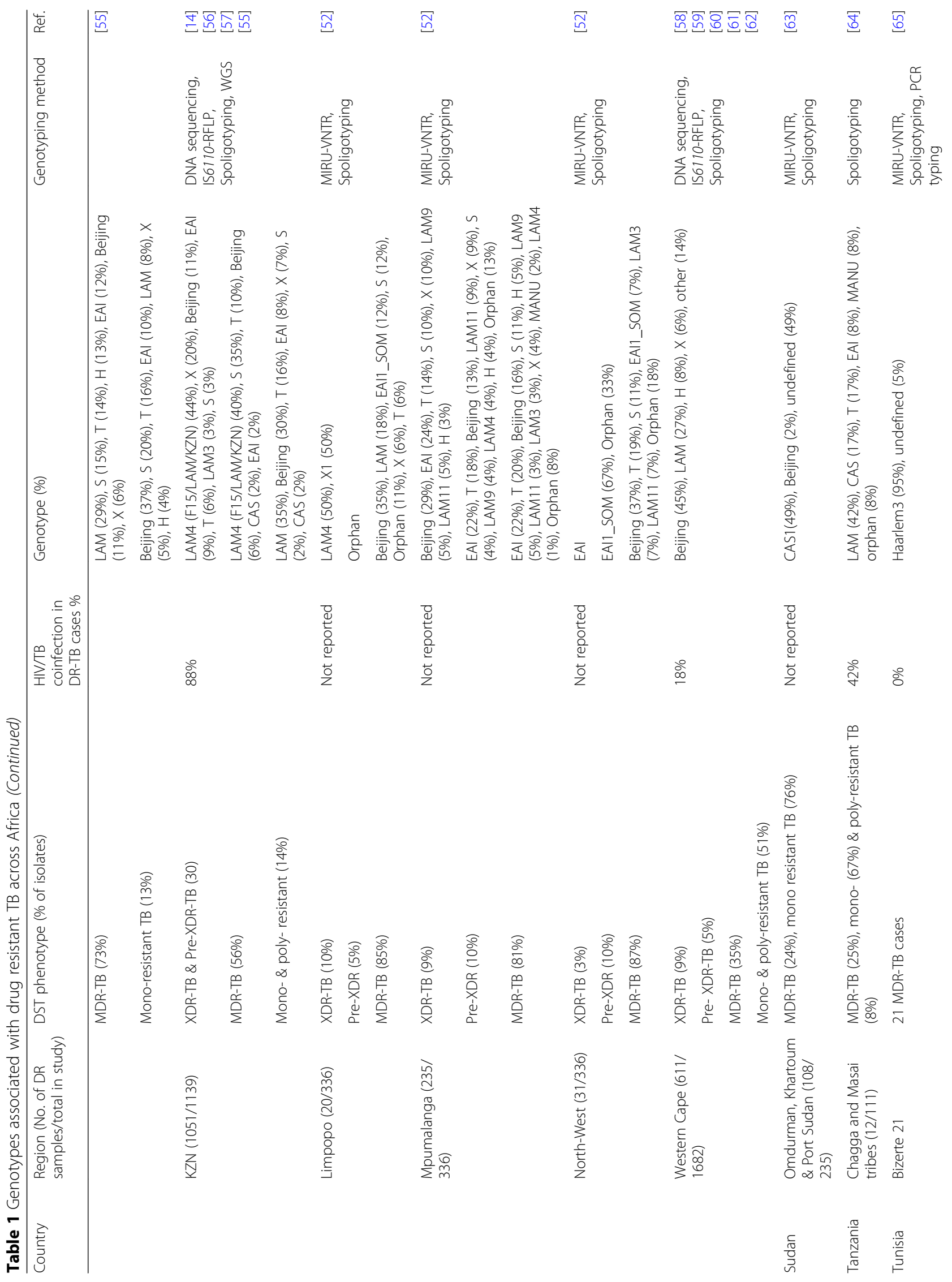




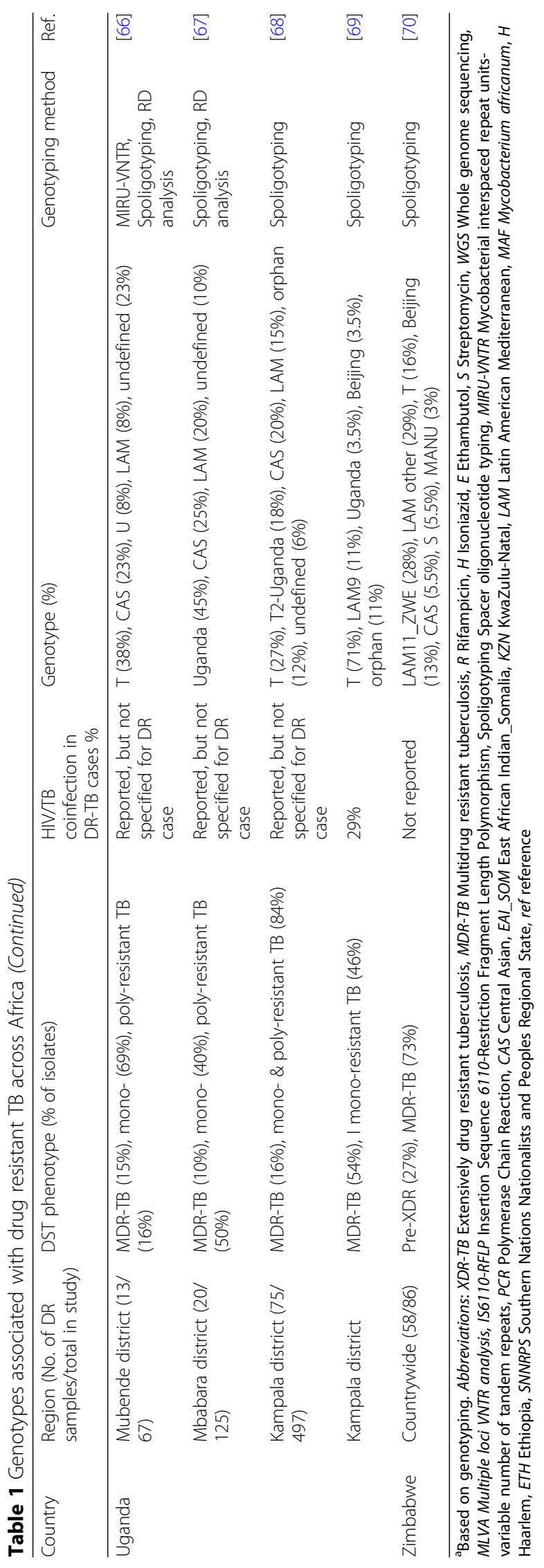




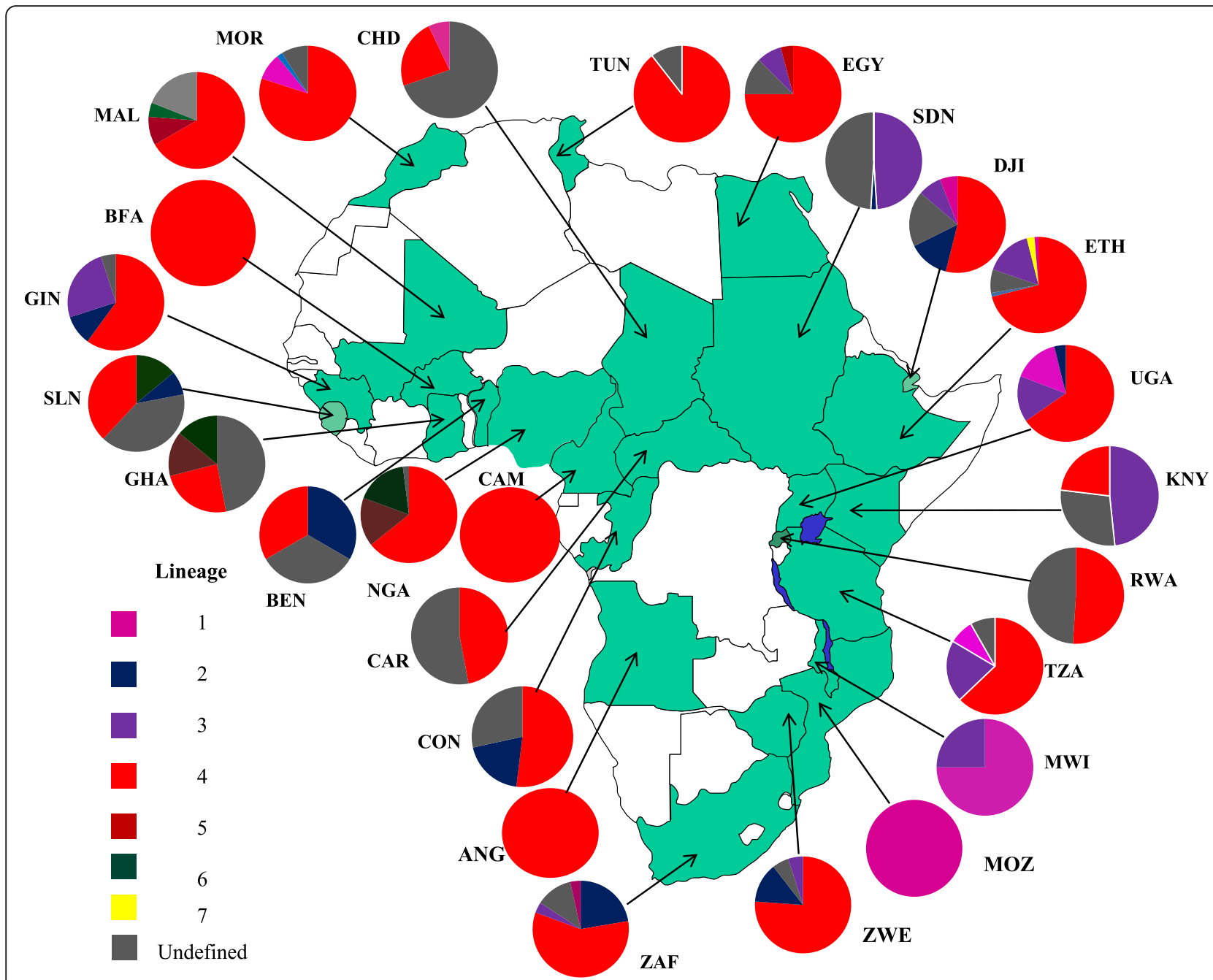

Fig. 1 Distribution of M. tuberculosis strains according to the 7 major lineages. Varying genotyping tools were used to characterise isolates including spoligotyping, MIRU-VNTR, PCR typing, and WGS, further described in Table 1. Note: Figure generated from references listed in Table 1. Countries highlighted in green are countries with published data on the molecular epidemiology of drug resistant TB in Africa

associated with XDR-TB while LAM11_ZWE is associated with MDR-TB in parts of Zimbabwe [54, 61, 70].

A high degree of clustering of drug resistant TB isolates has been observed in parts of Africa [23, 39, 40, $75]$; this is of great concern as it implies that there is recent and ongoing transmission of drug resistant TB strains within the region. Furthermore, a correlation between drug resistant strains in the adult population and in children has been demonstrated [62], suggestive of adult to child transmission. There is however very limited molecular typing data on drug resistant TB amongst children and household contacts of drug resistant TB patients in the rest of Africa to confirm this.

Modern lineages (East Asian, EAI and Euro American) have been associated with drug resistance in Central and West Africa (Figs. 1 and 2) [18, 21], regions predominantly associated with Mycobacterium africanum (MAF)
[18, 21, 35, 37]. Lineage 5 (West-Africa 1) and 6 (WestAfrica 2) however continue to predominate in West Africa and are largely associated with drug susceptible $\mathrm{TB}$ [24, 36, 46, 49]. The introduction of these drug resistant "modern strains" threatens management of drug resistant $\mathrm{TB}$ in the region $[22,31,67,68,76]$.

\section{Application of molecular methods to describe} transmission dynamics of drug resistant tuberculosis in Africa

Acquired MDR- and XDR-TB

There is evidence that acquisition of MDR-and XDR-TB also plays an important role in the burden of drug resistant TB in endemic regions of Africa [77-81]. Inadequate treatment has been shown to be a significant driving force in the development of drug resistant TB, driven by factors such as poor adherence to treatment, diagnosis 


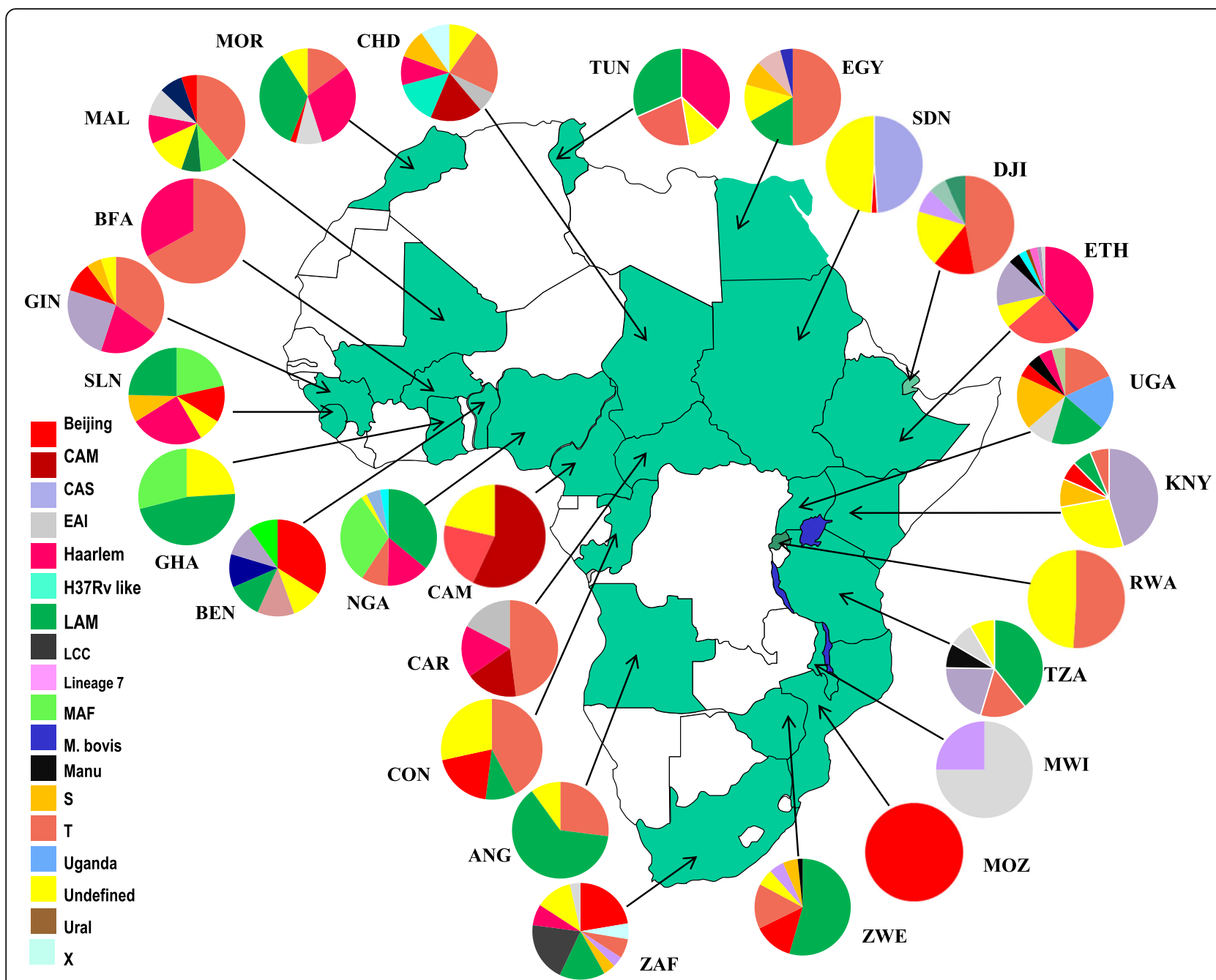

Fig. 2 Genotypic distribution of drug resistant M. tuberculosis isolates characterised across Africa; largely based on spoligotyping. Note: Figure generated from references listed in Table 1. Countries highlighted in green are countries with published data on the molecular epidemiology of drug resistant TB

delay and low quality anti-TB drugs [82, 83]. The severity of drug resistance in South Africa has been demonstrated to be much higher than other parts of Africa, this could be related to South Africa being the first country to administer second-line treatment on the continent in 2001 [84], and could be also be related to better reporting in South Africa.

The WHO recommends the use of a standardized TB treatment regimen which has been adopted by most countries in the region [2]. In the absence of laboratory monitoring and surveillance, mainly due to poor infrastructure and lack of resources, the risk of acquiring resistance is heightened in high TB burden settings [19, 82, 85]. Further, standardized TB treatment has been shown to be unsuccessful in preventing the spread of drug resistant TB $[83,86]$. Therefore, there is a need to implement routine DST and surveillance, supported by molecular epidemiology, for active case finding and to guide effective $\mathrm{TB}$ treatment in high risk population groups. On the contrary, a standardized shorter MDRTB regimen has been demonstrated to be highly effective, with a treatment success rate of $89 \%$ in Cameroon, a high MDR-TB setting [87].

\section{Outbreaks}

Drug resistant strains of $M$.tuberculosis have been linked with six distinct outbreaks in parts of Africa (Table 2) $[19,56,59,60,65,82]$. Outbreaks are characterised by sporadic spread of a particular strain of drug resistant TB unlike ongoing transmission which is characterised by constant spread of strains over a longer period of time. A prominent outbreak in Tugela Ferry KZN (mostly amongst HIV positive individuals) involving the F15/ LAM4/KZN lineage, brought global focus onto XDR-TB 


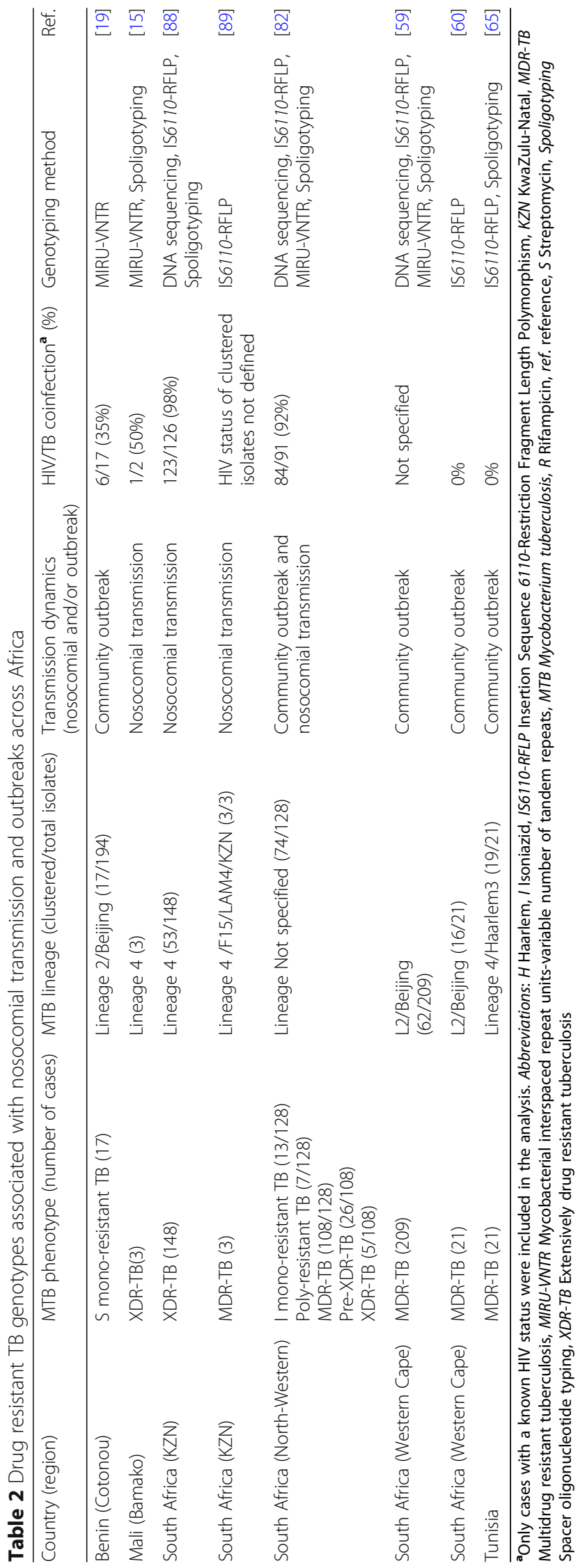


and revealed that XDR-TB strains are transmissible [56]. The main factors associated with the outbreak were an inadequate TB control program coupled with a high HIV prevalence in the affected population [56]. This stresses the need for improved TB infection prevention and control (IPC) measures, together with rapid diagnostics in the successful control of TB in general and XDR-TB in particular.

Outbreaks in vulnerable population groups of institutionalized and HIV positive individuals have also been documented [56, 82]. High clustering rates of drug resistant isolates were observed in a mining community which had a high rate of HIV sero-positive individuals (Table 2) [82]. The outbreak was as a result of an inefficient TB control program and diagnosis delay with the biannual chest radiography screening only diagnosing $30 \%$ of TB cases in this group of miners [82]. Recommendations have since been made to improve detection and to promote parallel treatment of TB and HIV in high risk groups [82].

Community outbreaks of MDR-TB in HIV seronegative, non-institutionalized individuals have also been reported $[19,60]$. Molecular investigations have revealed diversity in genotypes associated with outbreaks of drug resistant TB (Table 2). Genotypes initially identified to be responsible for drug resistant $\mathrm{TB}$ outbreaks have been demonstrated to re-emerge in communities as was the case in Tunisia [90]. A subsequent MDR-TB Haarlem strain outbreak was reported amongst the post-outbreak patients' population group in which the same strain was identified as the progenitor [90]. The findings of these drug resistant TB outbreak studies emphasise that MDR$\mathrm{TB}$ and indeed other drug resistant TB outbreaks are not limited to specific population groups such as the immunocompromised and the institutionalized [60, 65, 90].

There is some evidence that particular bacterial genotypes are associated with outbreaks. The Beijing genotype for instance, which is endemic in parts of South Africa, was linked to an outbreak of MDR-TB at a school in the Western Cape Province [59]. Molecular characterization confirmed that all isolates belonged to cluster R220 [59]. The genotype was further associated with a streptomycinresistant outbreak in Benin (Table 2) [19]. The occurrence of an outbreak caused by the Beijing genotype in West Africa further highlights the regional emergence of "modern strains" which appear highly virulent and pose a potential threat to TB control efforts in the region.

While host and strain genetics may play a role in driving outbreaks, inappropriate treatment, non-compliance to treatment and delays in diagnosis are amongst risk factors that have been linked to outbreaks within the continent $[56,60,82]$.

\section{Nosocomial transmission}

The extremely limited data on nosocomial transmission of drug resistant $\mathrm{TB}$ in Africa is alarming and places emphasis on the need for molecular epidemiological studies in these high risk settings. Hospital-acquired drug resistant TB has been reported in Africa (Table 2) $[15,82,88,89]$. An outbreak of the XDR-TB F15/LAM4/ KZN strain was described in a district hospital in Tugela Ferry, KZN, South Africa [88]. Epidemiological links for $82 \%$ of the patients were made and clustering was observed in $92 \%$ of strains [88]. The major risk factors that have been associated with hospital-acquired drug resistant TB are lack of proper IPC measures such as overcrowded wards, poor ventilation and delayed diagnosis $[15,88]$. This coupled with the high HIV prevalence experienced in most TB endemic regions makes nosocomial transmission a significant driving force in the transmission of drug resistant TB strains.

Rather than a single point-source outbreak, social network analysis has revealed that patients linked to nosocomial transmissions have a high degree of community interconnectedness $[82,88,91]$. This implies that transmission is occurring both in the community and in the health care facilities (Table 2). Prolonged exposure to patients with drug resistant $\mathrm{TB}$ and frequent, concurrent hospital admissions were common in most XDR-TB patients providing strong evidence that nosocomial transmission had occurred [88, 91].

Transmission of TB and drug resistant TB in particular is not only limited to patients receiving care and treatment in health care facilities but has been described in healthcare workers (HCWs) [92]. HCWs are at an increased risk of acquiring drug resistant $\mathrm{TB}$ at the work place, especially in the absence of effective IPC measures [93]. It has been demonstrated that diabetes mellitus and HIV infection are common co-morbidities in HCWs that were infected with MDR-TB in a teaching hospital in South Africa [92]. Other factors that have been associated with occupational acquisition of drug resistant $\mathrm{TB}$ and TB in general include: increased contact with patients who typically present to the health care facility when they are highly infectious, complacency and low awareness of self-risk typically seen in longer-serving HCWs [92, 93].

Recommendations made towards improved control measures are to prevent transmission through early diagnosis of resistant $\mathrm{TB}$, minimize congregation areas in hospitals by redesigning wards and out-patient areas and use of personal protective equipment [89, 91-93].

\section{Migration}

Migration has been demonstrated to play a critical role in the spread of drug resistant TB strains globally, with the majority of cases being reported in high-income countries originating from economic migrants from high TB burden countries [94]. There is abundant literature from high-income countries owing to excellent $\mathrm{TB}$ 
surveillance and monitoring [94]. In Africa however, there is very limited information on the impact of migration on transmission of drug resistant TB; this is mainly due to poor surveillance and monitoring. Further, migrant populations typically have poor access to health care and social structures.

Lineages and strains that had previously not been described in particular population groups have been hypothesised to have been introduced to various regions by immigrants $[39,86,94]$. However, the absence of baseline data makes it rather difficult to prove this hypothesis as there is very limited data on drug resistant genotypes that are in circulation within Africa. On the other hand, migration is rife in Africa, mainly due to political instability, civil wars and poverty, and it poses a major concern in the fight against TB and drug resistant TB in particular $[95,96]$.

Drug resistant strains with streptomycin resistance were detected in a refugee camp in Kenya [39]. Upon comparison to strains in the general populace, the refugee strains were unique to the camp [39]. The nomadic nature of refugees means that they are highly capable of spreading drug resistant strains [95]. There is a higher possibility of refugees failing to complete treatment due to their drifting nature and instability. Further, there is a possibility that the transmission of drug resistant strains is facilitated by a poor TB control program in the country of origin and/or in the refugee camp [39, 87, 95, 97].

Migration is not only an important factor in transmission of drug resistant $\mathrm{TB}$ across country borders and across continents, it has also been demonstrated to be an important means of transmission within countries as a result of movement to new cities and provinces in search of better employment opportunities and better health care facilities [39, 53]. For instance, the F15/ LAM4/KZN strain has been shown to be widespread both in districts of KZN and in surrounding areas [53, 98]. Further, transmission of drug resistant TB strains has been demonstrated between provinces and districts in South Africa [99, 100]. This stresses a need for rigorous screening of migrants coming from high TB endemic regions and also calls for development and implementation of TB IPC polices in congregate settings in high TB burden regions. However, the above mentioned recommendations are currently not feasible in most African countries due to the porosity of the borders; therefore it is recommended that employers be more vigilant with screening of migrant workers.

\section{Discussion}

The emergence and spread of drug resistant TB strains in the form of MDR-and XDR-TB continue to hinder global efforts to curb the disease; such as the WHO End TB Strategy which aims to reduce deaths associated with
TB as well as cut down on new TB cases [1]. The application of molecular epidemiological tools has enabled a better understanding of the global phylogeography of TB [13-16]. In Africa however, there is very limited and sporadic data for the genotypes associated with drug resistant TB. It is important for African countries to implement rigorous drug resistant TB surveillance systems for early case detection and treatment as well as monitoring of drug resistance trends. Routine surveillance would better inform TB control programs on the incidence of drug resistant TB in a given population.

Knowledge of the genotypes in circulation within a given population and the transmission dynamics of drug resistant $\mathrm{TB}$ would be important in guiding policy makers on the efficacy of the current treatment regimen and will help identify deficiencies in national TB control programs. Most studies under review used spoligotyping which offers a low resolution of clusters. Overall, WGS provides a superior level of understanding strain relatedness compared to IS6110-RFLP and spoligotyping. There is an urgent need to build in-country capacity to enable molecular investigations to be conducted locally using more advanced techniques of WGS. This would require laboratory capacity and training of laboratory and research personnel and would further require local and international funding.

Genetic diversity of $M$.tuberculosis strains has been demonstrated across Africa implying that diverse genotypes are driving the epidemiology of drug resistant TB across the continent. There are variations from region to region and particular genotypes have been demonstrated to be more predominant in certain countries and regions. There is a high degree of genetic diversity in the predominant strains in West Africa with both ancient and modern strains being associated with drug resistant TB [10, 20, 37, 45].

The Beijing and LAM genotypes are widespread across Africa demonstrating the ability of these "modern strains" to adapt and spread easily [17, 38, 54, 60]. It is however worth noting that the strain relatedness or transmission dynamics of these genotypes are not fully understood due to the lack of highly discriminatory tools of WGS in the reviewed studies. In contrast, the "ancient strains" such as MAF strains are largely restricted to West Africa where these strains are mostly associated with drug susceptible TB $[10,45,46]$. A similar observation is made with the Haarlem genotype which is associated with drug resistant TB in East and North Africa [26, 65].

The drug resistant TB epidemic in Africa has been attributed to several drivers, including socio-economic factors (poverty, overcrowded living conditions) and inefficient TB IPC policies (inappropriate treatment, lack of surveillance, diagnostic and treatment delay). MDR$\mathrm{TB}$ case finding and treatment remain a challenge in 
Africa with high TB and high MDR-TB burden countries falling short on treatment enrolment of new MDRTB cases, mainly due to the lack of adequate DST [1]. This highlights the urgent need for development and implementation of TB IPC policies in high-risk population groups and also calls for strengthening of outbreak response measures.

There remains a large pool of MDR- and XDR-TB cases that are untreated and are a potential source of drug resistant TB in the various communities [1]. There is a need for united efforts from the continent to improve case detection and treatment for prevention and control of drug resistant TB. Further, high mortality rates have been observed in MDR- and XDR-TB patients and this is worsened by co-infection with HIV [56]. This places emphasis on the need to strengthen the integration of HIV/TB screening and treatment in Africa.

The main challenge for TB activities across the continent is the lack of adequate funding. The majority of countries receive limited funding toward the national TB program with almost a third of the budget being unfunded on average in Africa [1]. Addressing this shortcoming will require collaborative efforts from global funders as well as domestic support from local government. Concerns regarding international funding increased following the proposed budget cuts after the election of Donald Trump as the president of the USA and after the" Brexit" vote in the UK $[101,102]$. Changes from the major global TB funders could result in the disintegration of already weak TB control programs in developing countries across the world.

Political instability is a source for concern as it leads to failing of health care infrastructure which in turn results in poor surveillance and treatment efforts. This has been demonstrated in migrant population groups with high rates of untreated drug resistant TB being found in these groups [94]. There is a need to develop and implement rigorous $\mathrm{TB}$ screening and treatment of migrants and TB suspects across Africa. This is however made difficult by the poor laboratory infrastructure such as lack of rapid diagnostic techniques for these highly mobile population groups.

\section{Conclusions}

Through molecular epidemiology, it has been demonstrated that drug resistant TB which is endemic in parts of Africa is both acquired and transmitted. Acquired drug resistant TB is largely driven by inadequate treatment, as seen in the case of standardized treatment in the absence of DST results, and non-adherence to treatment. On the other hand, drug resistant TB has been demonstrated to be transmitted in communities and hospital outbreaks have been reported mainly due to poor IPC measures. On average, the treatment success rates for MDR- and XDR-TB are low for Africa, 54 and $28 \%$ respectively.

The gap in knowledge on the transmission dynamics and molecular epidemiology of drug resistant TB across the continent is a hindrance in the management of drug resistant TB and calls for improved surveillance efforts. Molecular epidemiological studies play an important role in understanding the transmission dynamics of drug resistant TB across Africa, and will play a part in addressing this knowledge gap. Addressing these key knowledge gaps will guide effective TB treatment in high risk population groups. Additional studies are required to better understand the epidemiology and associated factors of drug resistant TB in Africa as a whole.

\section{Abbreviations}

CAM: Cameroon; CAR: Central African Republic; CAS: Central Asian; pDST: Phenotypic drug susceptibility testing; E: Ethambutol; EAl: East African Indian; EAl1_SOM: East African Indian_Somalia; ETH: Ethiopia; FQ: Fluoroquinolone; H or INH: Isoniazid; Km: Kanamycin; KZN: KwaZuluNatal; LAM: Latin American Mediterranean; LCC: Low copy clade; MAF: Mycobacterium africanum.; LPA: Line probe assay; MDR: Multidrug resistant; NATs: Nucleic acid tests; R or RIF: Rifampicin; RFLP: Restriction fragment length polymorphism; RR: Rifampicin resistant; S: Streptomycin; Spoligotyping: Spacer oligonucleotide typing; TB: Tuberculosis; WGS: Whole genome sequencing; WHO: World Health Organisation; XDR: Extensively drug resistant; Z: Pyrazinamide

\section{Acknowledgements}

The authors are grateful for the valuable suggestions made by Matthew Bates, Violet Chihota and Igor Mokrousov during manuscript preparation.

\section{Authors' contributions}

NKC, RW, ES and SS conceived and designed the review. NKC and RW selected the studies, extracted and analysed the data. NKC wrote the first draft of the manuscript. ES, SS, RW and MKM contributed to the interpretation of the results and revisions of the manuscript. All authors have read and approved the final version of the manuscript.

\section{Funding}

The authors acknowledge the South African Medical Research Council Centre for Tuberculosis Research and the Department of Science and Technology/National Research Foundation Centre of Excellence for Biomedical Tuberculosis Research for financial support for this work. SLS is funded by the South African Research Chairs Initiative of the Department of Science and Technology and National Research Foundation (NRF) of South Africa, award number UID 86539. The content is solely the responsibility of the authors and does not necessarily represent the official views of the NRF. NKC was funded by the Organisation for Women in Science for the Developing World (OWSD) and National Research Foundation (NRF) of South Africa.

Availability of data and materials

All data generated or analysed during this study are included in this published article, refer to Table 1.

Ethics approval and consent to participate Not applicable.

Consent for publication

Not applicable.

Competing interests

The authors have declared that they have no competing interest. 


\section{Received: 21 October 2019 Accepted: 14 April 2020}

\section{Published online: 13 May 2020}

\section{References}

1. World Health Organization. Global tuberculosis report. Geneva: WHO press 2018.

2. World Health Organization. Treatment guidelines for multidrug- and rifampicin-resistant tuberculosis. 2018 update. Geneva: WHO press; 2018.

3. Aung KJ, Van Deun A, Declercq E, Sarker MR, Das PK, Hossain MA, Rieder HL. Successful '9-month Bangladesh regimen' for multidrug-resistant tuberculosis among over 500 consecutive patients. Int J Tuberc Lung Dis. 2014;18:1180-7.

4. World Health Organization. The shorter MDR-TB regimen. Geneva: WHO press; 2016.

5. Menzies HJ, Moalosi G, Anisimova V, Gammino V, Sentle C, Bachhuber MA et al. Increase in anti-tuberculosis drug resistance in Botswana: results from the fourth national drug resistance survey. Int J Tuberc Lung Dis. 2014;18(9): 1026-33.

6. Sanchez-Padilla E, Dlamini T, Ascorra A, Rüsch-Gerdes S, Tefera ZD, Calain P, et al. High prevalence of multidrug-resistant tuberculosis, Swaziland, 20092010. Emerg Infect Dis. 2012;18:29-37.

7. Samo Gudo P, Cuna Z, Coelho E, Maungate S, Borroni E, Miotto P, et al. Is MDR-TB on the rise in Mozambique? Results of a national drug resistance survey. Eur Respir J. 2011;38(1):222-4.

8. South African Tuberculosis Drug Resistance Survey 2012-2014 Sandringham, South Africa, National Institute for Communicable Diseases. http://www. nicd.ac.za. accessed May 182019.

9. Kapata N, Mbulo G, Cobelens F, de Haas P, Schaap A, Mwamba P, et al. The second Zambian national tuberculosis drug resistance survey - a comparison of conventional and molecular methods. Tropical Med Int Health. 2015;20(11):1492-500.

10. Supply $P$, Lesjean S, Savine E, Kremer K, van Soolingen D, Locht C. Automated high-throughput genotyping for study of global epidemiology of Mycobacterium tuberculosis based on mycobacterial interspersed repetitive units. J Clin Microbiol. 2001;39:3563-71.

11. van Embden JD, Cave MD, Crawford JT, Dale JW, Eisenach KD, Gicquel B, et al. Strain identification of Mycobacterium tuberculosis by DNA fingerprinting: recommendations for a standardized methodology. J Clin Microbiol. 1993; 31(2):406-9.

12. Kamerbeek J, Schouls L, Kolk A, van Agterveld M, van Soolingen D, et al. Simultaneous detection and strain differentiation of Mycobacterium tuberculosis for diagnosis and epidemiology. J Clin Microbiol. 1997;35(4): 907-14

13. Cole ST, Brosch R, Parkhill J, Garnier T, Churcher C, Harris D, et al. Deciphering the biology of Mycobacterium tuberculosis from the complete genome sequence. Nature. 1998;393(6685):537-44.

14. Cohen KA, Abeel T, Manson McGuire A, Desjardins CA, Munsamy V, Shea TP, Walker BJ, et al. Evolution of extensively drug-resistant tuberculosis over four decades: whole genome sequencing and dating analysis of Mycobacterium tuberculosis isolates from KwaZulu-Natal. PLoS Med. 2015; 12(9):e1001880.

15. Diarra B, Toloba Y, Konate B, Sanogo M, Togo ACG, Camara F, et al. Extensively drug resistant tuberculosis in Mali: a case report. BMC Res Notes. 2017;10(1):561

16. Traore B, Diarra B, Dembele BP, Somboro AM, Hammond AS, Siddiqui S, et al. Molecular strain typing of Mycobacterium tuberculosis complex in Bamako. Mali Int J Tuberc Lung Dis. 2012;16(7):911-6.

17. Perdigão J, Clemente S, Ramos J, Masakidi P, Machado D, Silva C, et al. Genetic diversity, transmission dynamics and drug resistance of Mycobacterium tuberculosis in Angola. Sci Rep. 2017;7:42814.

18. Affolabi D, Sanoussi N, Codo S, Sogbo F, Wachinou P, Massou F, Kehinde A, Anagonou S. First insight into a nationwide genotypic diversity of Mycobacterium tuberculosis among previously treated pulmonary tuberculosis cases in Benin, West Africa. Can J Infect Dis Med Microbiol. 2017;2017:3276240.

19. Affolabi D, Faïhun F, Sanoussi N, Anyo G, Shamputa IC, Rigouts L, et al. Possible outbreak of streptomycin resistant Mycobacterium tuberculosis Beijing in Benin. Emerg Infect Dis. 2009;15(7):1123-5.

20. Godreuil S, Torrea G, Terru D, Chevenet F, Diagbouga S, Supply P, et al. First molecular epidemiology study of Mycobacterium tuberculosis in Burkina Faso. J Clin Microbiol. 2007:45(3):921-7.
21. Gehre F, Ejo M, Fissette K, de Rijk P, Uwizeye C, Nduwamahoro E, et al. Shifts in Mycobacterial populations and emerging drug-resistance in West and Central Africa. PLoS One. 2014;9(12):e110393.

22. Koro Koro F, Um Boock A, Kaiyven AL, Noeske J, Gutierrez C, Kuaban C, et al. Genetic structure and drug susceptibility patterns of Mycobacterium tuberculosis complex strains responsible of human pulmonary tuberculosis in the major rearing region in Cameroon. Biomed Res Int. 2016;2016: 2904832.

23. Ba Diallo A, Ossoga GW, Daneau G, Lo S, Ngandolo R, Djaibé CD, et al. Emergence and clonal transmission of multi-drug-resistant tuberculosis among patients in Chad. BMC Infect Dis. 2017:17(1):579.

24. Diguimbaye C, Hilty M, Ngandolo R, Mahamat HH, Pfyffer GE, Baggi F, et al. Molecular characterization and drug resistance testing of Mycobacterium tuberculosis isolates from Chad. J Clin Microbiol. 2006;44(4):1575-7.

25. Aubry A, Sougakoff W, Bodzongo P, Delcroix G, Armand S, Millot G, et al. First evaluation of drug-resistant Mycobacterium tuberculosis clinical isolates from Congo revealed misdetection of fluoroquinolone resistance by line probe assay due to a double substitution T80A-A90G in GyrA. PLoS One. 2014;9(4):e95083.

26. Blouin Y, Hauck Y, Soler C, Fabre M, Vong R, Dehan C, et al. Significance of the identification in the Horn of Africa of an exceptionally deep branching Mycobacterium tuberculosis clade. PLoS One. 2012;7(12):e52841.

27. Millán-Lou MI, Ollé-Goig JE, Tortola MT, Martin C, Samper S. Mycobacterial diversity causing multi- and extensively drug-resistant tuberculosis in Djibouti, horn of Africa. Int J Tuberc Lung Dis. 2016;20(2):150-3.

28. Cooksey RC, Abbadi SH, Woodley CL, Sikes D, Wasfy M, Crawford JT, Mahoney F. Characterization of Mycobacterium tuberculosis complex isolates from the cerebrospinal fluid of meningitis patients at six fever hospitals in Egypt. J Clin Microbiol. 2002;40(5):1651-5.

29. Abbadi S, Rashed HG, Morlock GP, Woodley CL, Shanawy OE, Cooksey RC. Characterization of IS6110 restriction fragment length polymorphism patterns and mechanisms of antimicrobial resistance for multidrug-resistant isolates of Mycobacterium tuberculosis from a major reference hospital in Assiut, Egypt. J Clin Microbiol. 2001;39(6):2330-4.

30. Tessema B, Beer J, Merker M, Emmrich F, Sack U, Rodloff A. Molecular epidemiology and transmission dynamics of Mycobacterium tuberculosis in Northwest Ethiopia: new phylogenetic lineage found in Northwest Ethiopia. BMC Infect Dis. 2013;13:131.

31. Beyene D, Bergval I, Hailu E, Ashenafi S, Yamuah L, Aseffa A, et al. Identification and genotyping of the etiological agent of tuberculous lymphadenitis in Ethiopia. J Infect Dev Ctries. 2009;3(6):412-9.

32. Workalemahu B, Berg S, Tsegaye W, Abdissa A, Girma T, Abebe M, Aseffa A. Genotype diversity of Mycobacterium isolates from children in Jimma, Ethiopia. BMC Res Notes. 2013;6:352.

33. Ali S, Beckert P, Haileamlak A, Wieser A, Pritsch MN, et al. Drug resistance and population structure of $M$. tuberculosis isolates from prisons and communities in Ethiopia. BMC Infect Dis. 2016;16(1):687.

34. Otchere ID, Asante-Poku A, Osei-Wusu S, Baddoo A, Sarpong E, Ganiyu AH, et al. Detection and characterization of drug-resistant conferring genes in Mycobacterium tuberculosis complex strains: a prospective study in two distant regions of Ghana. Tuberculosis (Edinb). 2016;99:147-54.

35. Asante-Poku A, Otchere ID, Osei-Wusu S, Sarpong E, Baddoo A, Forson A, et al. Molecular epidemiology of Mycobacterium africanum in Ghana. BMC Infect Dis. 2016;16:385

36. Yeboah-Manu D, Asante-Poku A, Bodmer T, Stucki D, Koram K, Bonsu F, et al. Genotypic diversity and drug susceptibility patterns among $M$. tuberculosis complex isolates from SouthWestern Ghana. PLoS One. 2011; 6(7):e21906

37. Ejo M, Gehre F, Barry MD, Sow O, Bah NM, Camara M, et al. First insights into circulating Mycobacterium tuberculosis complex lineages and drug resistance in Guinea. Infect Genet Evol. 2015;33:314-9.

38. Githui WA, Jordaan AM, Juma ES, Kinyanjui P, Karimi FG, Kimwomi J, et al. Identification of MDR-TB Beijing/W and other Mycobacterium tuberculosis genotypes in Nairobi. Kenya Int J Tuberc Lung Dis. 2004;8(3):352-60.

39. Githui WA, Hawken MP, Juma ES, Godfrey-Faussett P, Swai OB, Kibuga DK, et al. Surveillance of drug-resistant tuberculosis and molecular evaluation of transmission of resistant strains in refugee and non-refugee populations in north-eastern Kenya. Int J Tuberc Lung Dis. 2000:4(10):947-55.

40. Guerra-Assunção JA, Crampin AC, Houben RM, Mzembe T, Mallard K, Coll F, et al. Large-scale whole genome sequencing of $M$. tuberculosis provides insights into transmission in a high prevalence area. Elife. 2015;4:e05166. 
41. Togo ACG, Kodio O, Diarra B, Sanogo M, Coulibaly G, Bane S, et al. The most frequent Mycobacterium tuberculosis complex families in Mali (2006-2016) based on spoligotyping. Int J Mycobacteriol. 2017;6(4):379-86.

42. Tazi L, Reintjes R, Bañuls AL. Tuberculosis transmission in a high incidence area: a retrospective molecular epidemiological study of Mycobacterium tuberculosis in Casablanca, Morocco. Infect Genet Evol. 2007;7(5):636-44.

43. Bouklata N, Supply P, Jaouhari S, Charof R, Seghrouchni F, Sadki K, et al. Molecular typing of Mycobacterium tuberculosis complex by 24-locus based MIRU-VNTR typing in conjunction with spoligotyping to assess genetic diversity of strains circulating in Morocco. PLoS One. 2015;10(8):e0135695.

44. Viegas SO, Machado A, Groenheit R, Ghebremichael S, Pennhag A, Gudo PS, et al. Mycobacterium tuberculosis Beijing genotype is associated with HIV infection in Mozambique. PLoS One. 2013;8(8):e71999.

45. Thumamo BP, Asuquo AE, Abia-Bassey LN, Lawson L, Hill V, Zozio T, et al. Molecular epidemiology and genetic diversity of Mycobacterium tuberculosis complex in the Cross River state, Nigeria. Infect Genet Evol. 2012;12(4):671677.

46. Lawson L, Zhang J, Gomgnimbou MK, Abdurrahman ST, Le Moullec S, Mohamed F, et al. A Molecular epidemiological and genetic diversity study of tuberculosis in Ibadan, Nnewi and Abuja, Nigeria. PLoS One. 2012;7(6): e38409.

47. Senghore M, Otu J, Witney A, Gehre F, Doughty EL, Kay GL, et al. Wholegenome sequencing illuminates the evolution and spread of multidrugresistant tuberculosis in Southwest Nigeria. PLoS One. 2017;12(9):e0184510.

48. Gafirita J, Umubyeyi AN, Asiimwe BB. A first insight into the genotypic diversity of Mycobacterium tuberculosis from Rwanda. BMC Clin Pathol. 2012; 12:20.

49. Homolka S, Post E, Oberhauser B, George AG, Westman L, Dafae F, et al. High genetic diversity among Mycobacterium tuberculosis complex strains from Sierra Leone. BMC Microbiol. 2008:8:103.

50. Kvasnovsky CL, Cegielski JP, Erasmus R, Siwisa NO, Thomas K, der Walt ML. Extensively drug-resistant TB in eastern cape, South Africa: high mortality in HIV-negative and HIV-positive patients. J Acquir Immune Defic Syndr. 2011; 57(2):146-52.

51. Klopper M, Warren RM, Hayes C. Gey van Pittius NC, Streicher EM, Müller B, et al. Emergence and spread of extensively and totally drug-resistant tuberculosis, South Africa. Emerg Infect Dis. 2013;19(3):449-55.

52. Said HM, Kock MM, Ismail NA, Mphahlele M, Baba K, Omar SV, et al. Molecular characterization and second-line antituberculosis drug resistance patterns of multidrug-resistant Mycobacterium tuberculosis isolates from the northern region of South Africa. J Clin Microbiol. 2012;50(9):2857-62.

53. Kamudumuli PS, Beylis N, Blann L, Duse A. Molecular typing of drugsusceptible and -resistant Mycobacterium tuberculosis in Johannesburg, South Africa. Int J Tuberc Lung Dis. 2015;19(7):834-40.

54. Marais BJ, Mlambo CK, Rastogi N, Zozio T, Duse AG, Victor TC, et al. Epidemic spread of multidrug-resistant tuberculosis in Johannesburg, South Africa. J Clin Microbiol. 2013:51(6):1818-25.

55. Chihota VN, Muller B, Mlambo CK, Pillay M, Tait M, Streicher EM, et al. Population structure of multi- and extensively drug-resistant Mycobacterium tuberculosis strains in South Africa. J Clin Microbiol. 2012;50:995-1002.

56. Gandhi NR, Moll A, Sturm AW, Pawinski R, Govender T, Lalloo U, et al. Extensively drug-resistant tuberculosis as a cause of death in patients coinfected with tuberculosis and HIV in a rural area of South Africa. Lancet. 2006;368:1575-80

57. O'Donnell MR, Pillay M, Pillay M, Werner L, Master I, Wolf A, et al. Primary capreomycin resistance is common and associated with early mortality in patients with extensively drug-resistant tuberculosis in KwaZulu-Natal, South Africa. J Acquir Immune Defic Syndr. 2015;69(5):536-43.

58. Streicher EM, Warren RM, Kewley C, Simpson J, Rastogi N, Sola C, et al. Genotypic and phenotypic characterization of drug-resistant Mycobacterium tuberculosis isolates from rural districts of the Western Cape Province of South Africa. J Clin Microbiol. 2004:42:891-4.

59. Johnson R, Warren R, Strauss O, Jordaan A, Falmer A, Beyers N, et al. An outbreak of drug resistant tuberculosis caused by a Beijing strain in the Western cape, South Africa. Int J Tuberc Lung Dis. 2006;10(12):1412-4.

60. van Rie A, Warren R, Beyers N, Gie R, Classen C, Richardson M, et al. Transmission of a multidrug-resistant Mycobacterium tuberculosis strain resembling "strain w" among noninstitutionalized, human immunodeficiency virus-seronegative patients. J Infect Dis. 1999;180:1608-15.
61. Johnson R, Warren R, van der Spuy G. Gey van Pittius N, Theron D, Streicher $\mathrm{E}$, et al. Drug-resistant tuberculosis epidemic in the Western cape driven by a virulent Beijing genotype strain. Int J Tuberc Lung Dis. 2010;14(1):119-21.

62. Marais BJ, Victor TC, Hesseling AC, Barnard M, Jordaan A, Brittle W, et al. Beijing and Haarlem genotypes are overrepresented among children with drug-resistant tuberculosis in the Western Cape Province of South Africa. J Clin Microbiol. 2006;44(10):3539-43.

63. Sharaf Eldin GS, Fadl-Elmula I, Ali MS, Ali AB, Salih AL, Mallard K, et al. Tuberculosis in Sudan: a study of Mycobacterium tuberculosis strain genotype and susceptibility to anti-tuberculosis drugs. BMC Infect Dis. 2011; 11:219.

64. Kibiki GS, Mulder B, Dolmans WM, de Beer JL, Boeree M, Sam N, et al. M tuberculosis genotypic diversity and drug susceptibility pattern in HIVinfected and non-infected patients in Northern Tanzania. BMC Microbiol. 2007;7:51.

65. Mardassi H, Namouchi A, Haltiti R, Zarrouk M, Mhenni B, Karboul A, et al. Tuberculosis due to resistant Haarlem strain, Tunisia. Emerg Infect Dis. 2005; 11(6):957-61.

66. Muwonge A, Malama S, Johansen TB, Kankya C, Biffa D, Ssengooba W, et al. Molecular epidemiology, drug susceptibility and economic aspects of tuberculosis in Mubende district, Uganda. PLoS One. 2013:8(5):e64745.

67. Bazira J, Asiimwe BB, Joloba ML, Bwanga F, Matee MI. Mycobacterium tuberculosis spoligotypes and drug susceptibility pattern of isolates from tuberculosis patients in South-Western Uganda. BMC Infect Dis. 2011;11:81.

68. Lukoye D, Katabazi FA, Musisi K, Kateete DP, Asiimwe BB, Okee M, et al. The T2 Mycobacterium tuberculosis genotype, predominant in Kampala, Uganda, shows negative correlation with antituberculosis drug resistance. Antimicrob Agents Chemother. 2014;58(7):3853-9.

69. Asiimwe BB, Ghebremichael S, Kallenius G, Koivula T, Joloba ML. Mycobacterium tuberculosis spoligotypes and drug susceptibility pattern of isolates from tuberculosis patients in peri-urban Kampala, Uganda. BMC Infect Dis. 2008;8:101.

70. Sagonda T, Mupfumi L, Manzou R, Makamure B, Tshabalala M, Gwanzura L, et al. Prevalence of extensively drug resistant tuberculosis among archived multidrug resistant tuberculosis isolates in Zimbabwe. Tuberc Res Treat. 2014:2014:349141.

71. Van Rie A, Warren R, Richardson M, Gie RP, Enarson DA, Beyers N, et al. Classification of drug-resistant tuberculosis in an epidemic area. Lancet. 2000;356(9223):22-5.

72. Pillay M, Sturm AW. Evolution of the extensively drug-resistant F15/LAM4/ KZN strain of Mycobacterium tuberculosis in KwaZulu-Natal, South Africa. Clin Infect Dis. 2007:45(11):409-14.

73. Stavrum R, Mphahlele M, Ovreås K, Muthivhi T, Fourie PB, Weyer K, Grewal HM. High diversity of Mycobacterium tuberculosis genotypes in South Africa and preponderance of mixed infections among ST53 isolates. J Clin Microbiol. 2009;47(6):1848-56.

74. Guerra-Assunção JF, Houben RM, Crampin AC, Mzembe T, Mallard K, Coll F, et al. Recurrence due to relapse or reinfection with Mycobacterium tuberculosis: a whole-genome sequencing approach in a large, population based cohort with a high HIV infection prevalence and active follow-up. J Infect Dis. 2015:211(7):1154-63.

75. Nouvel LX, Kassa-Kelembho E, Dos Vultos T, Zandanga G, Rauzier J, Lafoz C, et al. Multidrug-resistant Mycobacterium tuberculosis, Bangui, Central African Republic. Emerg Infect Dis. 2006;12(9):1454-6.

76. Abbadi S, Hadidy G, Gomaa N, Cooksey R. Strain differentiation of Mycobacterium tuberculosis complex isolated from sputum of pulmonary tuberculosis patients. Int J Infect Dis. 2009;13(2):236-42.

77. Namouchi A, Karboul A, Mhenni B, Khabouchi N, Haltiti R, Ben Hassine R, et al. Genetic profiling of Mycobacterium tuberculosis in Tunisia: predominance and evidence for the establishment of a few genotypes. J Med Microbiol. 2008:57(Pt 7):864-72.

78. Pérez-Lago L, Izco S, Herranz M, Tudó G, Carcelén M, Comas I, et al. A novel strategy based on genomics and specific PCR reveals how a multidrugresistant Mycobacterium tuberculosis strain became prevalent in Equatorial Guinea 15 years after its emergence. Clin Microbiol Infect. 2017;23(2):92-7.

79. Glynn JR, Crampin AC, Yates MD, Traore H, Mwaungulu FD, Ngwira BM, et al. The importance of recent infection with Mycobacterium tuberculosis in an area with high HIV prevalence: a long-term molecular epidemiological study in northern Malawi. J Infect Dis. 2005;192(3):480-7. 
80. Wilkinson D, Pillay M, Davies GR, Sturm AW. Resistance to antituberculosis drugs in rural South Africa: rates, patterns, risks, and transmission dynamics. Trans R Soc Trop Med Hyg. 1996;90(6):692-5.

81. Streicher EM, Sampson SL, Dheda K, Dolby T, Simpson JA, Victor TC, et al. Molecular epidemiological interpretation of the epidemic of extensively drug-resistant tuberculosis in South Africa. J Clin Microbiol. 2015;53(11): 3650-3.

82. Calver AD, Falmer AA, Murray M, Strauss OJ, Streicher EM, Hanekom M, et al. Emergence of increased resistance and extensively drug-resistant tuberculosis despite treatment adherence, South Africa. Emerg Infect Dis. 2010;16(2):264-71.

83. Pietersen E, Peter J, Streicher E, Sirgel F, Rockwood N, Mastrapa B, et al. High frequency of resistance, lack of clinical benefit, and poor outcomes in capreomycin treated South African patients with extensively drug-resistant tuberculosis. PLoS One. 2015;10(4):e0123655.

84. Cox H, Dickson-Hall L, Jassat W, Moshabela M, Kielmann K, Grant A, et al. Drug-resistant tuberculosis in South Africa: history, progress and opportunities for achieving universal access to diagnosis and effective treatment. In: SAHR - 20 Year Anniversary Edition; 2017. p. 157-68.

85. Müller B, Chihota VN, Pillay M, Klopper M, Streicher EM, Coetzee G, et al. Programmatically selected multidrug-resistant strains drive the emergence of extensively drug-resistant tuberculosis in South Africa. PLoS One. 2013; 8(8):e70919.

86. loerger TR, Koo S, No EG, Chen X, Larsen MH, Jacobs WR Jr, et al. Genome analysis of multi- and extensively-drug-resistant tuberculosis from KwaZuluNatal, South Africa. PLoS One. 2009:4(11):e7778.

87. Kuaban C, Noeske J, Rieder H, et al. High effectiveness of a 12-month regimen for MDR-TB patients in Cameroon. Int J Tuberc Lung Dis. 2015;19: 517-24.

88. Gandhi NR, Weissman D, Moodley P, Ramathal M, Elson I, Kreiswirth BN, et al. Transmission of extensively drug-resistant tuberculosis in a rural hospital in South Africa. J Infect Dis. 2013;207(1):9-17.

89. Pillay M, Sturm AW. Nosocomial transmission of the F15/LAM4/KZN genotype of Mycobacterium tuberculosis in patients on tuberculosis treatment. Int J Tuberc Lung Dis. 2010;14(2):223-30.

90. Namouchi A, Haltiti $R$, Hawari D, Mardassi $H$. Re-emergence of the progenitors of a multidrug resistant outbreak strain of Mycobacterium tuberculosis among the post-outbreak case patients. J Infect Dis. 2010;201(3): 390-8.

91. Eshun-Wilson I, Zeier MD, Taljaard JJ, Barnes J. TB infection among staff at Tygerberg academic hospital, South Africa. South Afr J Epidemiol Infect. 2008:23(4):17-9.

92. von Delft A, Dramowski A, Khosa C, Kotze K, Lederer P, Mosidi T, et al. Why healthcare workers are sick of TB. Int J Infect Dis. 2015;32:147-51.

93. World Health Organization. WHO policy on TB infection control in healthcare facilities, congregate settings and households. Geneva: WHO press; 2009.

94. European Centre for Disease Prevention and Control/WHO Regional Office for Europe. Tuberculosis surveillance and monitoring in Europe 2016. Stockholm: European Centre for Disease Prevention and Control; 2016.

95. Cain KP, Marano N, Kamene M, Sitienei J, Mukherjee S, Galev A, et al. The movement of multidrug-resistant tuberculosis across borders in East Africa needs a regional and global solution. PLoS Med. 2015;12(2):e1001791.

96. Alene KA, Viney K, McBryde ES, Clements ACA. Spatial patterns of multidrug resistant tuberculosis and relationships to socio-economic, demographic and household factors in Northwest Ethiopia. PLoS One. 2017;12(2): e0171800.

97. Matteelli A, Lonnroth K, Mosca D, Getahun H, Centis R, DÁmbrosio, et al. Cameroon's multidrug-resistant tuberculosis treatment programme jeopardised by cross-border migration. Eur Respir J. 2016;47:686-8.

98. Shah NS, Auld SC, Brust JC, Mathema B, Ismail N, Moodley P, et al. Transmission of extensively drug-resistant tuberculosis in South Africa. N Engl J Med. 2017;376(3):243-53.

99. Moodley P, Shah NS, Tayob N, Connolly C, Zetola N, Gandhi N, et al. Spread of extensively drug-resistant tuberculosis in KwaZulu-Natal Province, South Africa. PLoS One. 2011;6(5):e17513.

100. Green E, Obi LC, Okoh Al, Nchabeleng M, de Villiers BE, Letsoalo T, et al. IS6110 restriction fragment length polymorphism typing of drug-resistant Mycobacterium tuberculosis strains from Northeast South Africa. J Health Popul Nutr. 2013;31(1):1-10.
101. Garmaise D. President Trump's proposed budget for FY 2019 includes cuts of $\$ 425$ million for the Global Fund. Aids Pan. http://www.aidspan.org/gfo article/president-trumps-proposed-budget-fy-2019-includes-cuts-425-millionglobal-fund. Accessed on 4th April 2018.

102. Fox B, Rountree C. EU-development-aid-faces-brexit-squeeze. Euractiv. https://www.euractiv.com/section/development-policy/news/eudevelopment-aid-faces-brexit-squeeze/. Accessed on 4th April 2018.

\section{Publisher's Note}

Springer Nature remains neutral with regard to jurisdictional claims in published maps and institutional affiliations.
Ready to submit your research? Choose BMC and benefit from:

- fast, convenient online submission

- thorough peer review by experienced researchers in your field

- rapid publication on acceptance

- support for research data, including large and complex data types

- gold Open Access which fosters wider collaboration and increased citations

- maximum visibility for your research: over $100 \mathrm{M}$ website views per year

At BMC, research is always in progress.

Learn more biomedcentral.com/submissions 